\title{
ESTUDO DA INJEÇÃO DE MISTURAS DE CASCA DE EUCALIPTO COM CARVÃO MINERAL EM ALTO-FORNO*
}

\author{
Ricardo dos Santos Oliveira ${ }^{1}$ \\ Carlos Frederico Campos de Assis ${ }^{2}$ \\ Paulo Santos Assis ${ }^{3}$
}

\section{Resumo}

Este trabalho foi realizado a partir da identificação de um problema ambiental, a alta concentração de gases do efeito estufa. Ao analisar as emissões nacionais de sistemas de energia, observou-se que o segmento da indústria de aço tem uma importante participação devido ao alto consumo de carvão metalúrgico e coque no balanço energético, mostrando a predominância de usinas à base de coque siderúrgico integrados. Depois de identificar algumas possíveis soluções para este problema ambiental, o projeto teve como objetivo utilizar cascas de eucalipto na injeção de finos pulverizados pelas ventaneiras de altos-fornos nas siderúrgicas. A utilização deste material como uma fonte de energia (combustível) no processo de redução de minério de ferro em altos-fornos, substituindo diretamente o carvão, apresenta uma solução viável para o sequestro de carbono. O eucalipto é uma fonte renovável, ao contrário do carvão mineral, e através da fotossíntese captura o gás $\mathrm{CO}_{2}$ da atmosfera, reduzindo a poluição causada pelos altos-fornos e participa no mercado de carbono. Assim, a empresa poderia participar do mercado de carbono, o que poderia resultar em um lucro anual superior apenas por este mecanismo. A casca do eucalipto é rico em carbono e complementa a oferta desse elemento para o processo de redução de minério. Assim, em teoria, o que esta pesquisa mostra é que a casca de eucalipto pode ser injetada em altos-fornos no lugar do carvão pulverizado, tornando este processo ser rentável para a empresa.

Palavras-chave: Carvão pulverizado; Injeção; Alto-forno; Casca de eucalipto.

\section{STUDY OF BARK EUCALYPTUS MIXTURES WITH COAL INJECTION IN BLAST FURNACE}

\begin{abstract}
This work was carried out from the identification of an environmental problem, the high concentration of greenhouse gases. By analyzing the national energy system emissions, it was observed that the segment of the steel industry has an important participation due to the high consumption of metallurgical coal and coke in the energy balance, showing the predominance of integrated steelmaking coke based plants. After identifying some possible solutions to this environmental issue, this project aimed to use barks of eucalyptus in the injection on tuyeres of blast furnaces of steel mills. The use of this material as an energy source (fuel) in the process of reduction of iron ore in blast furnaces, replacing directly coal, presents a viable solution to carbon sequestration. Eucalyptus is a renewable source, unlike coal, and through photosynthesis captures $\mathrm{CO}_{2}$ from the atmosphere, reducing the pollution caused by the blast furnace and participle in the carbon market. Thus the company could participate in the carbon market, which could result in a higher annual profit only by this mechanism. The bark of eucalyptus is rich in carbon and complements the provision of that element to the process of ore reduction. So, in theory, this research attempts to shows that barks of eucalyptus can be injected into blast furnaces in place of the pulverized coal, making this process being profitable for the company.

Keywords: Pulverized coal; Injection; Blast furnace; Bark eucalyptus.

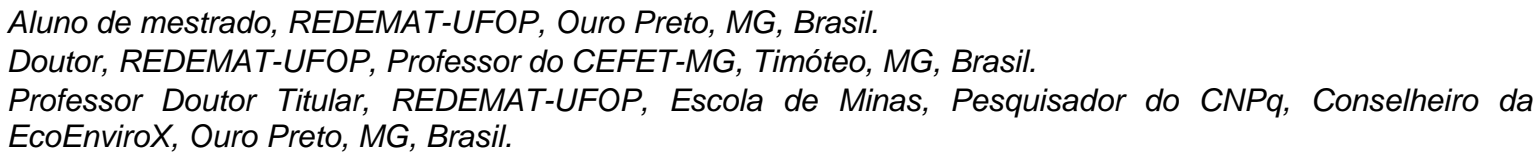




\section{INTRODUÇÃO}

Devido às atividades humanas, a concentração de gases de efeito estufa na atmosfera tem aumentado consideravelmente nos últimos anos, agravando o efeito estufa e contribuindo para o aquecimento global. Essas ações estão ligadas principalmente a queima de combustíveis fósseis. Para combater esses problemas ambientais entrou em vigor, em 2005, o Protocolo de Quioto. O objetivo do protocolo é, de forma simplificada, limitar as emissões de gases do efeito estufa e também estabelecer uma proposta de desenvolvimento para a sustentabilidade dos recursos naturais [1-3].

Dentre as medidas adotadas para reduzir o consumo de energia destaca a injeção de carvão pulverizado ( $\mathrm{PCl}$ ) em altos-fornos, que têm como objetivo reduzir o consumo de coque ou carvão vegetal, além de auxiliar no aumento da produtividade e redução de custos de produção. A injeção de carvão pulverizado é uma realidade e pode ser encontrada em alguns setores taxas de injeção da ordem de até $200 \mathrm{~kg} / \mathrm{t}$ de gusa [4].

Este trabalho teve como objetivo estudar a inserção de outra fonte de energia para a injeção nas ventaneiras de altos-fornos, como as misturas de biomassa de casca de eucalipto e carvão. A casca de eucalipto é um dos principais resíduos sólidos gerados pela produção de celulose. Logo, o uso deste resíduo no processo de injeção implicaria na redução do consumo de carvão mineral, oferecendo uma maior sustentabilidade econômica e ambiental na produção de ferro-gusa. Além disso, ele pode combinar técnicas de reflorestamento para sequestro de carbono e oxigênio devido à regeneração de práticas florestais realizadas pelas fábricas de celulose, onde o acúmulo de carbono fixo por hectare de eucalipto é de 10 toneladas [5].

\section{MATERIAIS E MÉTODOS}

Neste trabalho estudou-se o comportamento de mistura de carvão mineral e casca de eucalipto pulverizado para injeção em altos-fornos, inclusive os de pequeno porte com volume útil menor que $300 \mathrm{~m}^{3}$, considerando as condições restritivas reinantes nestes reatores.

Inicialmente as amostras passaram por um ensaio de granulometria com o objetivo de classificar todo material de granulometria entre $0,075 \mathrm{~mm}(200 \#)$ e $0,150 \mathrm{~mm}$ (100\#). Em seguida as amostras passaram pela estufa a fim de minimizar a umidade do material (abaixo de 5\%). As misturas entre carvão mineral e casca de eucalipto são de $25 \%, 50 \%$ e $75 \%$, para uma taxa de injeção de $50 \mathrm{~kg} / \mathrm{t}$ gusa, $100 \mathrm{~kg} / \mathrm{t}$ gusa e $150 \mathrm{~kg} / \mathrm{t}$ gusa.

Uma vez preparadas, as amostras foram submetidas à análise química imediata utilizando adaptações da EN 14774, EN 14775 e EN 15148. A análise química elementar foi levada a cabo usando uma adaptação da norma EN 15104 e EN 15289, o poder calorífico foi analisado usando a norma EN 14918 e as amostras seguiram para o Simulador de Injeção de Materiais Pulverizados em altos-fornos, ensaio realizado no Laboratório de Siderurgia da Escola de Minas / UFOP. O equipamento, mostrado na Figura 1, simula as condições existentes na injeção de materiais pulverizados em ventaneiras de altos-fornos, a fim de se determinar o índice de combustão do material em questão. Dessas condições podemos destacar:

- Baixo tempo de residência da partícula no jato de gás no raceway do altoforno. Este tempo é da ordem de 20 à $50 \mathrm{~ms}(=0,02$ a $0,05 \mathrm{~s})$; 
- Elevado gradiente térmico que o material pulverizado sofre quando é injetado nas ventaneiras. Este valor é da ordem de $10^{5} \mathrm{~K} / \mathrm{s}$.

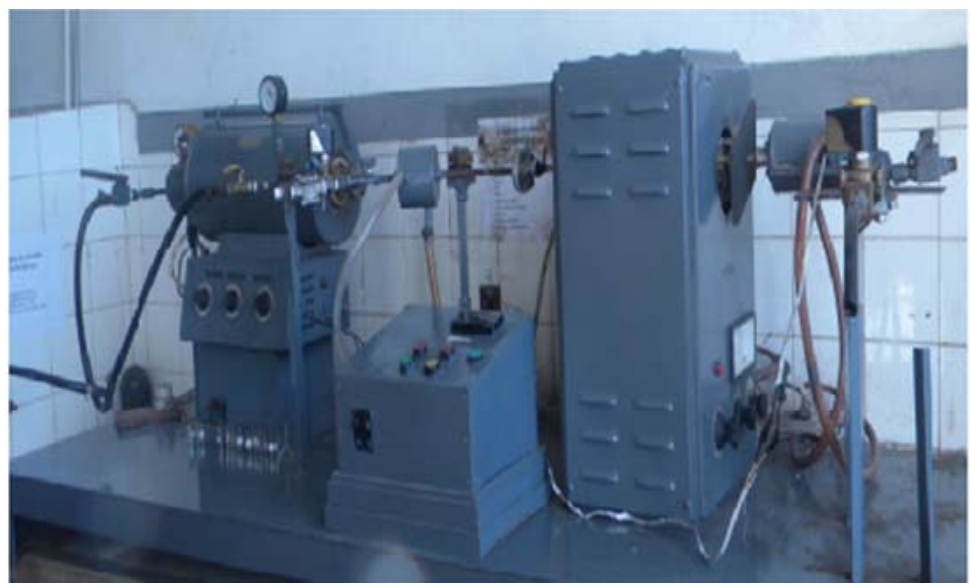

Figura 1. Simulador de injeção de materiais pulverizados em altos-fornos.

O equipamento utiliza dois fornos:

- Um forno de pré-aquecimento: forno do tipo Kanthal operado com uma variação de temperatura de 0 a $1250^{\circ} \mathrm{C}$. A temperatura do forno é monitorada por um controlador digital de temperatura, ativado por um termopar. A câmara de reação do forno é composta por um tubo de aproximadamente $41,5 \mathrm{~cm}$ de comprimento e $7,5 \mathrm{~cm}$ de diâmetro, sendo esta de aço inoxidável. O objetivo principal deste forno é fornecer calor ao oxigênio (em torno de $1000^{\circ} \mathrm{C}$ ) simulando a temperatura de sopro do alto-forno.

- Um forno que simula a zona de combustão capaz de operar a temperaturas acima de $1500^{\circ} \mathrm{C}$, sendo monitorado por um controlador digital de temperatura ativado por um termopar. A finalidade deste forno é simular as características da zona de combustão de um alto-forno.

Próximo à entrada do forno de pré-aquecimento existe um manômetro para ajustar e monitorar a pressão do gás, logo após este, existe um dispositivo de resfriamento operado com água para assegurar que o calor de dentro do forno de préaquecimento não seja conduzido ao gás antes dele chegar ao interior deste. Os dois fornos e a lança de injeção são interligados por tubos de aço inoxidável, sendo que no interior do forno de combustão existe um tubo de quartzo para resistir às altas temperaturas atingidas no interior deste. No fim do tubo do forno de combustão existe um filtro para remover a parcela do material não queimado e encaminhar o gás para a válvula eletromagnética a qual emite um pulso que encaminha o gás para ser coletado em uma ampola de vidro e depois segue para posterior análise no ORSAT, mostrado na Figura 2. O equipamento ORSAT trata-se de um conjunto de ampolas de vidro contendo um seu interior soluções necessárias para a captura do gás. Este sistema é interligado por tubos de vidro por onde o gás é forçado a passar, gerando assim, uma leitura no teor de $\mathrm{CO}, \mathrm{CO}_{2}, \mathrm{O}_{2}$ e $\mathrm{CH}_{4}$. As soluções utilizadas são de cloreto cúprico para o $\mathrm{CO}$, hidróxido de potássio para o $\mathrm{CO}_{2}$, pirogalol para $\mathrm{o}$ $\mathrm{O}_{2}$ e cloreto de sódio para o $\mathrm{CH}_{4}$. 


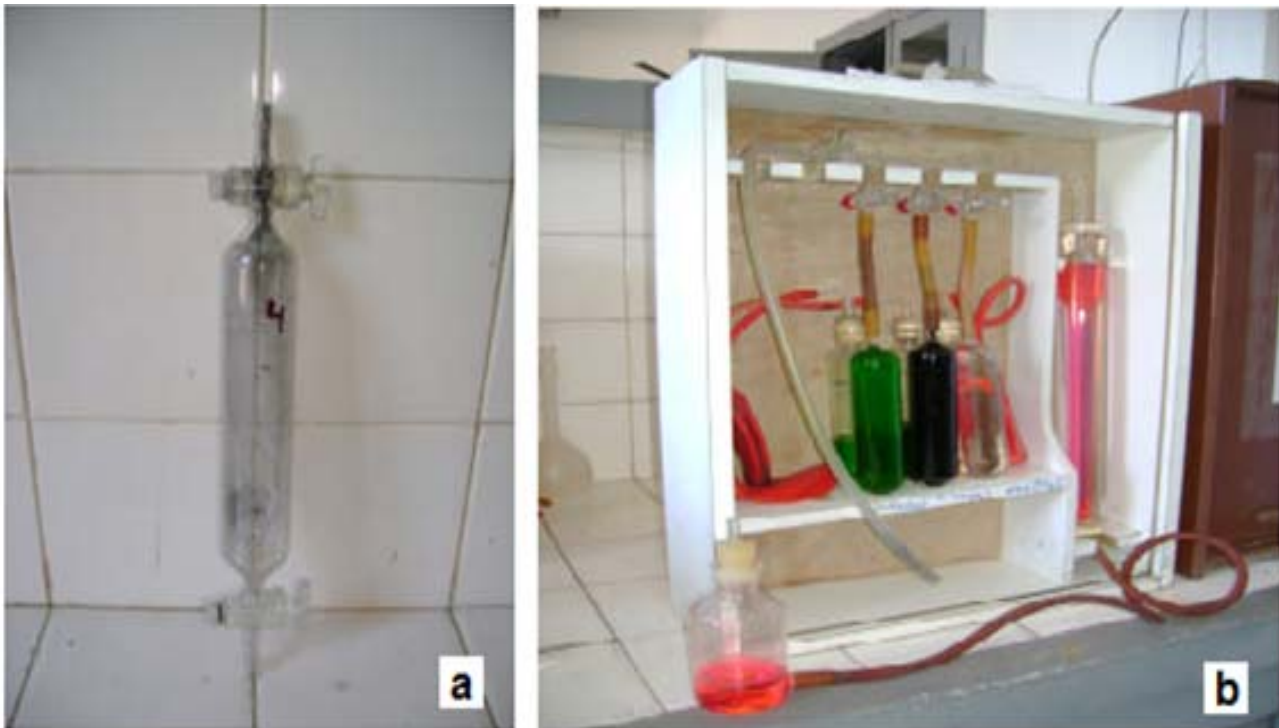

Figura 2. Ampola de vidro para coleta de gás (a) e analisador de gás ORSAT (b).

Após a análise, o cálculo do índice de combustão é feito pela Equação 1:

$\mathrm{IC}=\mathrm{K} *\left\{\left(\% \mathrm{CO}+\% \mathrm{CO}_{2}\right)^{*} \mathrm{n} /\left[\left(\mathrm{ma}^{*} \% \mathrm{C}_{\mathrm{f}} / 1200000\right)-\left(\% \mathrm{CH}_{4}{ }^{*} \mathrm{ng} / 1000\right)\right]\right\}(1)$

Em que:

- $\quad \mathrm{IC}=$ Índice de combustão;

- $\% \mathrm{CO}, \% \mathrm{CO}_{2}, \% \mathrm{CH}_{4}=$ Porcentagens dos gases produzidos;

- $\% \mathrm{C}_{\mathrm{f}}=$ Carbono fixo contido na amostra;

- $\mathrm{ng}$ = Número de mols do gás depois da experiência;

- $\mathrm{ma}=$ Massa da amostra de carbono injetada em miligramas;

- $\mathrm{K}=$ Constante função dos parâmetros do ensaio.

\section{RESULTADOS E DISCUSSÃO}

Os materiais voláteis são substâncias formadas pelos elementos químicos carbono, hidrogênio e oxigênio. Após a pirólise (endotérmica) do carvão liberam gases combustíveis e incombustíveis. Na tabela 1 observa-se que o material volátil da casca de eucalipto é 4,72 vezes maior que a do carvão mineral.

O carbono é um gerador de calor e participa indiretamente da redução da carga metálica. Geralmente quando o teor de carbono aumenta, aumenta a taxa de substituição e aumenta, também, a taxa de combustão. As necessidades de enriquecimento em oxigênio para manter a temperatura na zona de combustão diminuem quanto maior for o teor de carbono [6,7]. Observa-se na tabela 1 que o carbono fixo do carvão mineral é 4,47 vezes maior que da casca de eucalipto e o carbono elementar do carvão mineral é 1,65 vezes maior que da casca de eucalipto. $\mathrm{O}$ hidrogênio é um gerador de calor com menor potencialidade que o carbono. $O$ aumento do teor de hidrogênio dentro do alto-forno reduz a queda de pressão na rampa, a redução do $\mathrm{FeO}$ é menos endotérmica que a do carbono, com maior velocidade e em menor temperatura. Isso implica que pode ser utilizada menor temperatura de chama no alto-forno. Um ponto negativo é que altos teores de hidrogênio podem levar a grande quantidade de finos de coque na cuba do altoforno[6,7]. A Tabela 1 mostra que a casca de eucalipto possui um pouco mais de hidrogênio que o carvão mineral.

O aumento do teor de cinzas irá aumentar o volume da escória e aumentar o consumo de calor no alto-forno e, também, leva a um aumento no consumo de 
carbono, o que reduz a taxa de substituição, aumenta as necessidades de fluxantes e, consequentemente, diminui a produção $[6,7]$. Teores de cinza abaixo de $18 \%$ são aceitáveis. De acordo com a Tabela 1, os dois materiais apresentam teores menores. É importante lembrar que esses materiais podem ser misturados diminuindo o teor de cinza médio injetados no alto-forno, prática esta já usada nas siderúrgicas, com intuito, também, de diminuição de custo.

O enxofre (S) do combustível quando incorporado no ferro-gusa necessitará de dessulfuração posterior, na fabricação do aço. Para diminuir o teor de enxofre no ferro-gusa utiliza-se aumentar o volume da escória e sua basicidade, aumentado o custo de produção do alto-forno. O limite desejável para enxofre é de $0,8 \%$ total nas matérias-primas [6,7]. A Tabela 1 apresenta o teor de enxofre do carvão mineral e da casca de eucalipto menor que este limite.

O oxigênio (O) participa da combustão do carbono, hidrogênio e hidrocarbonetos existente no material pulverizado injetado no alto-forno. Sua presença é importantíssima para o aumento da taxa de injeção no alto-forno e diminuição da variação de pressão interna do alto-forno. Desta forma, o oxigênio existente nos materiais reagirá com as substâncias oxidáveis no momento da queima, economizando oxigênio a ser injetado pelas ventaneiras. É importante salientar que isso ocorre quando o oxigênio encontra-se puro $\left(\mathrm{O}_{2}\right)$. $\mathrm{Na}$ tabela 1 , a casca de eucalipto apresenta teor de oxigênio 12,28 vezes maior que o de carvão mineral.

Geralmente, a taxa de substituição aumenta quanto maior o poder calorífico dos carvões injetados. Carvões com alto poder calorífico aumentam o fluxo de calor na zona de combustão e, consequentemente, a temperatura de chama [7]. Através da Tabela 1 verifica-se, também, que o maior poder calorífico superior (PCS) é do carvão mineral.

Tabela 1. Resultados referentes às análises de poder calorífico, superfície específica, análise química elementar e imediata.

\begin{tabular}{c|c|c|c}
\hline \multicolumn{2}{c|}{ Análises } & Carvão mineral & $\begin{array}{c}\text { Casca de } \\
\text { eucalipto }\end{array}$ \\
\hline \multirow{3}{*}{ Elementar } & Carbono [\%] & 80,60 & 48,9 \\
\cline { 2 - 4 } & Hidrogênio [\%] & 3,85 & 5,29 \\
\cline { 2 - 4 } & ${ }^{*}$ Oxigênio [\%] & 3,34 & 41,02 \\
\cline { 2 - 4 } & Nitrogênio [\%] & 1,81 & 0,47 \\
\cline { 2 - 4 } & Enxofre [\%] & 0,30 & 0,25 \\
\hline \multirow{4}{*}{ Imediata } & Cinzas [\%] & 10,10 & 4,07 \\
\cline { 2 - 4 } & Materiais Voláteis [\%] & 16,87 & 79,60 \\
\cline { 2 - 4 } & Carbono fixo [\%] & 73,04 & 16,32 \\
\hline \multicolumn{2}{c}{ Poder Calorífico Superior [kcal/kg] } & 7442 & 4206 \\
\hline
\end{tabular}

*Oxigênio calculado por diferença.

Através da Tabela 2 observa-se que o aumento da taxa de injeção provoca uma diminuição da taxa de combustão de todos os materiais analisados. Isto é influenciado principalmente pelas condições extremamente severas e do oxigênio presente na raceway. Esses parâmetros influenciam negativamente na eficiência de combustão. Isto pode ser explicado pela menor relação $\mathrm{O} / \mathrm{C}$ presentes na zona de combustão, portanto gerando uma menor taxa [4].

Comparando os materiais puros (100\%), carvão mineral e casca de eucalipto, a Tabela 2 apresenta taxa de combustão maior para casca de eucalipto, para todos os valores analisados. Isso pode ser explicado pelo maior teor de materiais voláteis e menor teor de carbono fixo apresentado nas análises da casca de eucalipto. Isso pode ser visto também nas misturas, ou seja, quanto maior a quantidade de casca 
de eucalipto na mistura com carvão mineral, maior será a taxa de combustão, para cada taxa de injeção específica (50,100 e $150 \mathrm{~kg} / \mathrm{t}$ gusa). A mistura de $75 \%$ de casca de eucalipto e $25 \%$ de carvão mineral apresentou a melhor taxa de combustão para as taxas de injeção estudada. Assim, pode-se dizer que existe uma simbiose entre a pirólise e a combustão de materiais voláteis de ambos os materiais.

Tabela 2. Resultados da taxa de combustão para carvão mineral, casca de eucalipto e suas misturas.

\begin{tabular}{|c|c|c|c|c|}
\hline \multirow{3}{*}{ MATERIAIS } & \multirow{3}{*}{ MISTURAS(\%) } & \multicolumn{3}{|c|}{ TAXA DE INJEÇÃO (kg/t gusa) } \\
\hline & & 50 & 100 & 150 \\
\hline & & \multicolumn{3}{|c|}{ TAXA DE COMBUSTÃO (\%) } \\
\hline \multirow{4}{*}{$\begin{array}{l}\text { CASCA DE } \\
\text { EUCALIPTO }\end{array}$} & 25 & 88,4 & 85,6 & 71,2 \\
\hline & 50 & 89,7 & 88,1 & 74,5 \\
\hline & 75 & 90,8 & 88,5 & 78,1 \\
\hline & 100 & 89,5 & 87,3 & 76,7 \\
\hline $\begin{array}{l}\text { CARVÃO } \\
\text { MINERAL }\end{array}$ & 100 & 85,9 & 83,3 & 71,2 \\
\hline
\end{tabular}

\section{CONCLUSÃO}

Os resultados analisados mostram que a casca de eucalipto pode ser usada na injeção de finos pelas ventaneiras do alto-forno. A taxa de combustão foi melhor para a mistura de $75 \%$ de casca de eucalipto e $25 \%$ de carvão mineral. No caso ambiental, a casca de eucalipto, através do plantio de eucalipto, pode absorver $\mathrm{CO}_{2}$ da atmosfera através da fotossíntese. Com isso, reduzindo as emissões de gases do alto-forno através do equilíbrio de gases do efeito estufa.

\section{Agradecimentos}

Os autores deste artigo gostariam de agradecer ao Departamento de Pesquisa e Desenvolvimento da Usiminas pela análise elementar, a EcoEnviroX por apoiar o desenvolvimento deste estudo, ao CEFET-MG e a UFOP pelo apoio incondicional à inovação. A Fundação Gorceix, FAPEMIG e CNPq pelo apoio financeiro.

\section{REFERÊNCIAS}

1 Empresa de Pesquisa Energética - EPE. Caracterização do uso da Energia no Setor Siderúrgico Brasileiro. 2009 ; 1-89.

2 Centro de Gestão e Estudos Estratégicos - CGEE. Estudo Prospectivo do Setor Siderúrgico (2010-2025). 2009; 1-36.

3 Instituto Aço Brasil. Relatório de Sustentabilidade 2012. Concepção AMCE Negócios Sustentáveis. 2012; 1-93.

4 Assis PS, Martins BM, Vieira CB. Curso de injeção de materiais pulverizados em altosfornos. Belo Horizonte: Associação Brasileira de Metalurgia, Materiais e Minas; 2009.

5 Yoshida T, Turn SQ, Yors RS, Antal MJ. Banagrass versus eucalyptus wood volume equations for tree species in Europe. Silva Fennica Monographs. 2005;4: 1-63.

6 Gomes MLI. Avaliação da viabilidade técnica da utilização de misturas de carvão faxinal com importados para injeção em alto-forno. Dissertação de mestrado apresentada na Universidade Federal do Rio Grande do Sul no Programa de Pós-Graduação em Engenharia de Minas, Metalúrgica e de materiais - PPGEM. 2004; 1-111.

7 Machado JGMS. Estudo da reatividade e combustão de Carvões Minerais, Carvão Vegetal e misturas. Tese de Doutorado apresentada na Universidade Federal do Rio Grande do Sul, Programa de Pós-Graduação em Engenharia de Minas, Metalúrgica e de Materiais - PPGEM. 2009; 1-212. 